\title{
Effects of orofacial myofunctional therapy on the symptoms and physiological parameters of sleep breathing disorders in adults: a systematic review
}

Fabiane Kayamori ${ }^{(1)}$ Esther Mandelbaum Gonçalves Bianchini ${ }^{(1)}$

Pontifícia Universidade Católica de São Paulo (PEPG-PUCSP), São Paulo, SP, Brazil.

Research support source: National Postdoctoral Program/ Coordination for the Improvement of Higher Education Personnel (PNPD/CAPES).

Conflict of interest: Nonexistent

Received on: August 29, 2017 Accepted on: October 17, 2017

Mailing address:

Fabiane Kayamori

Alameda Jaú, 1767 , conjunto 51 ,

Cerqueira César

CEP: 01420-002 - São Paulo,

São Paulo, Brasil

E-mail:fabianekayamori@gmail.com

\section{ABSTRACT}

Recently, the orofacial myofunctional therapy (OMT) has appeared as a possible alternative treatment for obstructive sleep apnea (OSA). Systematic reviews are required to achieve scientific evidence, seeking to direct the decision on therapeutic issues. The aim of this study was to systematically review the literature about the OMT proposals in adults with OSA related to symptoms and physiological parameters. Data sources were Lilacs, MEDLINE, Pubmed, Cochrane and Scielo using the descriptors: obstructive sleep apnea; myofunctional therapy; oropharyngeal exercises; breathing exercises; upper airway exercises; speech therapy. Studies published from 2000 to 2017 that evaluated the treatment with isolated OMT in subjects with OSA were included, obligatorily with polysomnographic data, pre and post therapy. Eight studies, out of 124 articles, were eligible according to the criteria adopted. Two systematic reviews, one clinical trial, three randomized clinical trials, and two case reports were included. Six studies showed a decrease in the Apnea and Hypopnea Index (AHI), five studies showed improvement in the minimum Sp02, decrease in the Epworth Sleepiness Scale (ESS) and in snoring. OMT proposals refer to a three-month program changing the parameters related to partial reduction of AHI, ESS index, snoring, and partial increase of Sp02. There are few randomized studies.

Keywords: Obstructive Sleep Apnea; Snoring; Myofunctional Therapy; Speech, Language and Hearing Sciences; Oropharynx 


\section{INTRODUCTION}

Orofacial myofunctional therapy (OMT) is a set of techniques and procedures intended to change orofacial muscular and functional patterns using isotonic and isometric exercises for orofacial and oropharyngeal muscles targeting the functions of breathing, mastication, swallowing and speech'1.

For the past 10 years, Speech, Language and Hearing Sciences intervention using OMT have been presented in this field as one of the possible treatments for snoring and obstructive sleep apnea (OSA), with evidence found specially in studies on Sleep Breathing Dlsorders in adults ${ }^{1-4}$.

Every new field of study with its specific techniques needs researches that provide evidence of the benefits of each therapy. The first publications on OMT for obstructive sleep apnea date from $1999^{5}$, but the first randomized clinical trial (RCT) to use the therapy as alternative treatment for patients with moderate OSA was published in 2009'. The study reported a decrease of approximately $40 \%$ in the Apnea and hypopnea index (AHI), a reduction in cervical circumference, reduction in snoring intensity and frequency, reduction of daytime sleepiness and better sleep quality after the OMT program. Right after this first international publication, the same journal published an editorial questioning the benefits and objectives of OMT procedures for improving OSA ${ }^{6}$.

Physiologically, the pharynx is a highly collapsible area in the entirety of its extension. The activity of dilating pharynx muscles, especially the genioglossus and tensor palatini muscles oppose to the tendency of the pharynx to collapse as a protective mechanism. Changes in such mechanism are associated with the syndrome of obstructive sleep apnea disorder ${ }^{7}$. In that sense, OMT applied to OSA has the objective of strengthening the nasopharynx and oropharynx musculature contributing to reduce collapse of the airway during sleep ${ }^{1-4}$. However, the exact mechanisms by which OMT helps with Sleep Breathing Disorders are still not clear to this day.

Contemporary studies show OMT efficient results in improving the quality of life $^{2}$, in the reduction of intensity and frequency of snoring ${ }^{3}$ and in the better adherence of CPAP (Continuous Positive Airway Pressure) ${ }^{4}$. Such studies endorse the Speech, Language Therapist interest in this field and validate the presence of that professional in the interdisciplinary realm of Sleep Breathing Disorders, especially in Brazil with the existence of a specific certification for Speech,
Language and Hearing Sciences in the field of sleep disorders ${ }^{8}$.

At the present stage, systematic reviews are necessary to attest the level of scientific evidence of OMT effects in OSA and in snoring, as well as to set methodological parameters for the decision-making in therapy matters. However, such parameters are not always clear or coincident, making difficult a consistent verification of OMT effects for individuals with Sleep Breathing Disorders.

The objective of this study is to systematically analyze the scientific literature available on OMT programs for adults with Sleep Breathing Disorders, their effects on symptoms and physiological parameters, trying to argue for the relevance of the practicebased evidence (PBE).

\section{METHODS}

\section{Research strategies}

The fundamental questions that guide this literature review are:

"What are the methodological parameters in orofacial myofunctional therapy programs for Sleep Breathing Disorders?"

"What are the effects of the isolated orofacial myofunctional therapy in adults considering symptoms and physiological parameters of Sleep Breathing Disorders?".

Our search was performed in the following online databases: "Literatura Latino-Americana e do Caribe em Ciências da Saúde" (Lilacs); "Medical Literature Analysis and Retrieval System Online" (MEDLINE), "US National Library of Medicine National Institutes Health" (Pubmed), "Cochrane Library" (Cochrane) and "Scientific Electronic Library" (Scielo) and we have selected the studies published between the year 2000 and April 2017.

The descriptors in Health Sciences (DeCs) used for retrieving the articles, language limiters considered for Portuguese and English languages, were: apneia obstrutiva do sono (obstructive sleep apnea) [All fields]; terapia miofuncional (myofunctional therapy) [All fields]; exercícios (exercises) [All fields]; exercícios orofaríngeos (oropharyngeal exercises) [All fields]; exercícios respiratórios/ /exercícios da via aérea (breathing exercises / upper airway exercises [All fields]; Fonoaudiologia (Speech, Language and Hearing Sciences / speech therapy) [All fields]. The 
search was performed with associated descriptors (e/and).

\section{Selection criteria}

The selection of studies published followed the steps described below:

The search for materials according to the associate descriptors and that had been published between the year 2000 to 2017 (April) in the referred databases with full version available online; the selection of studies whose titles and abstracts were related to the proposed subject; observation of inclusion and exclusion criteria; reading and analysis of the full text articles.

The considered articles should published in Portuguese or English and approach the methodological parameters for the OMT programs related to Sleep Breathing Disorders or present studies describing the procedures and effects of isolated OMT in adults considering the symptoms and physiological parameters of Sleep Breathing Disorders (snoring and/or OSA) necessarily reporting polysomnographic data (pre and post therapy), at least for the Apnea and Hypopnea Index (AHI).

Repeated articles recovered from different databases were not considered. An initial selection was made after reading of titles and abstracts and exclusion of those that did not match the criteria. The full text articles were downloaded and the studies were read and analyzed in their entirety. The references were evaluated, the studies were identified and listed.

\section{Data analysis}

The following topics were tabulated for the articles' analysis: name of authors, year of publication, information on the type of study, study risk of bias (considering selection, performance, detection, friction and publishing biases), number of subjects, demographic characteristics (gender, age), type of Sleep Breathing Disorder, level of OSA severity, methodological parameters with respect to therapeutic procedures and description of results post OMT.

A specific protocol was developed for the present research based on the selected articles and trying to answer the question on the methodological parameters that guide OMT proposals for Sleep Breathing Disorders.

The specific research protocol based on methodological parameters included:

Therapeutic parameters: procedures, frequency and period of therapy, therapy follow up;

Parameters for evaluation and reevaluation:

Physiologic parameters: anthropometric measurements such as body mass index (BMI) and cervical circumference (cc) pre and post OMT, polysomnographic data such as Apnea and Hypopnea Index (AHI) for each hour of sleep and minimum blood oxygen saturation $(\mathrm{SpO} 2)$ and period with $\mathrm{SpO} 2$ under 90\% pre and post OTM;

Symptomatology: data on daytime sleepiness (Epworth Sleepiness Scale) $)^{9}$ and snoring reported by complaint or part of Berlin questionnaire (referring to intensity and frequency $)^{10}$.

\section{LITERATURE REVIEW}

One hundred and twenty four articles were screened considering the methodology for this literature review, initially excluding the studies that did not involve snoring and/or OSA $(\mathrm{N}=28)$ and that did not provide some form of therapy $(\mathrm{N}=67) .29$ potentially relevant studies were set apart and their references checked for other studies not present in our initial search. 10 more studies were included. After verifying the total of 39 articles, 31 of them were eliminated and 8 articles were kept for detailed analysis.

The fluxogram (Figure 1) illustrates the trajectory of the present study. It is interesting to point out that 4 studies involve specifically the applicability and results of OMT for children ${ }^{11-14}$, two case-control reports ${ }^{13,14}$ and two retrospective studies ${ }^{11,12}$. 


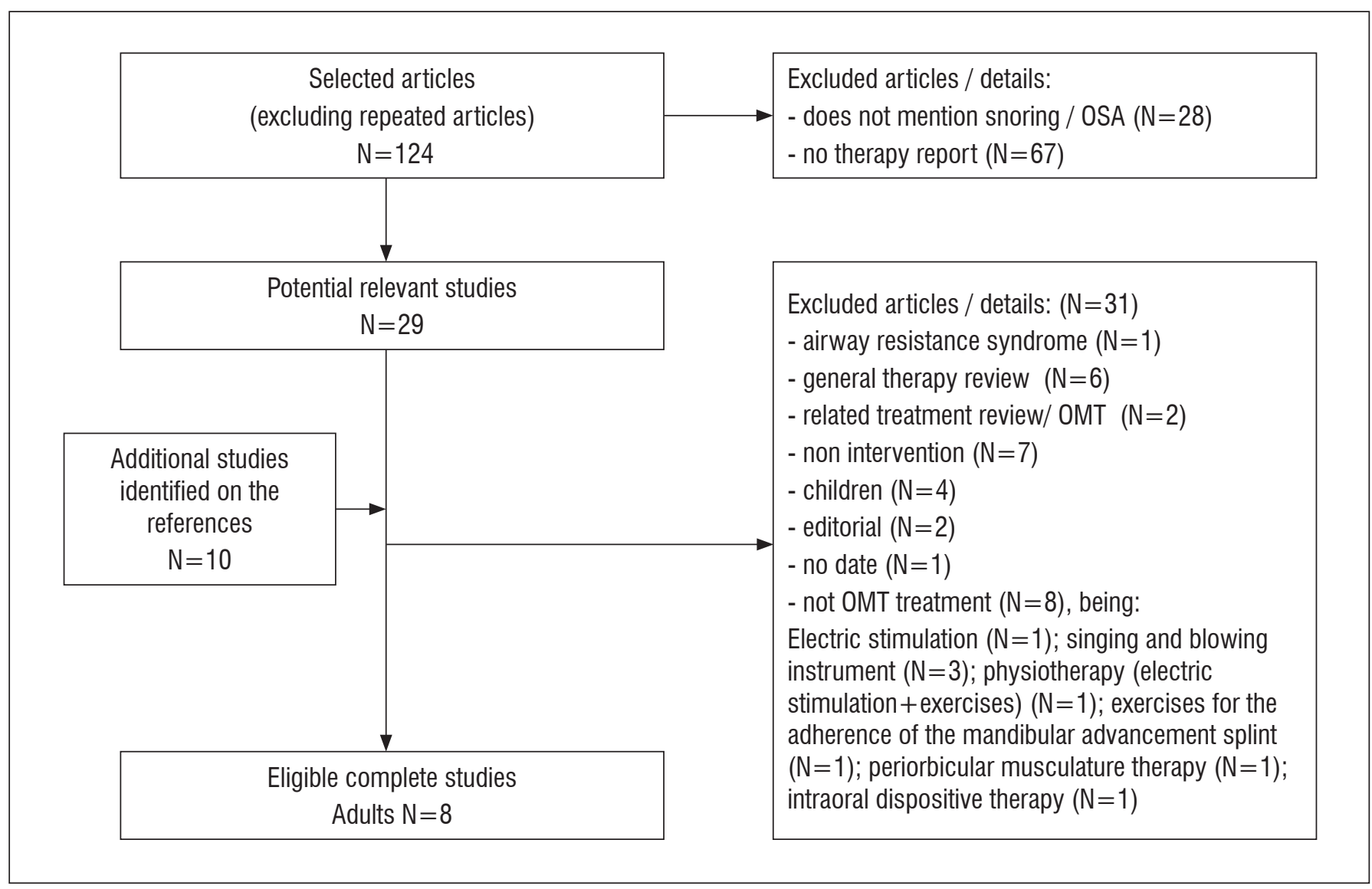

Figure 1. Systematic literature review information fluxogram: studies selection stage

Considering the focus of the present systematic literature review on the effects of isolated OMT for adults with OSA, 8 studies were considered, two of them with systematic literature review ${ }^{15,16}$, three $\mathrm{RCT}^{1-4}$, one clinical study ${ }^{17}$ and two case reports ${ }^{18,19}$. A description of the studies can be found in Tables 1 and 2 .

Table 1. Eligible literature review articles description

\begin{tabular}{ccccc}
\hline Author, year & \multicolumn{1}{c}{ Objective } & Meta-analysis & $\begin{array}{c}\text { Number of listed } \\
\text { articles }\end{array}$ & Conclusion \\
\hline $\begin{array}{c}\text { Camacho et al, } \\
2015^{(16)}\end{array}$ & $\begin{array}{c}\text { Systematic literature review } \\
\text { considering OMT for the } \\
\text { treatment of OSA in children and } \\
\text { adults performing meta-analysis } \\
\text { of polysomnography, snoring and } \\
\text { sleepiness }\end{array}$ & Yes & 9 & $\begin{array}{c}\text { Data on the adults: } \\
\text { myofunctional therapy reduces AHI } \\
\text { in approximately } 50 \% \text {, improves } \\
\mathrm{SpO}_{2} \text { and snoring. }\end{array}$ \\
$\begin{array}{c}\text { Lalbuza et al, } \\
\text { Literature review on methods } \\
\text { of treatment for OSA improving } \\
\text { musculature tonus as revealed in } \\
\text { the AHI. }\end{array}$ & No & 3 & $\begin{array}{c}\text { No accepted scientific evidence that } \\
\text { the methods are effective for AHI } \\
\text { decrease under 5. }\end{array}$ \\
\hline
\end{tabular}


Table 2. Eligible clinical studies description considering type of study and biases

\begin{tabular}{|c|c|c|c|c|c|c|c|}
\hline & & $\begin{array}{c}\text { Selection } \\
\text { bias }\end{array}$ & $\begin{array}{c}\text { Selection } \\
\text { bias }\end{array}$ & $\begin{array}{c}\text { Performance } \\
\text { bias }\end{array}$ & Detection bias & Attrite bias & Report bias \\
\hline Author, year & study & $\begin{array}{l}\text { Random } \\
\text { sequence } \\
\text { generator }\end{array}$ & $\begin{array}{l}\text { Omitted } \\
\text { allocation }\end{array}$ & $\begin{array}{l}\text { Participants and } \\
\text { professional } \\
\text { blinding }\end{array}$ & $\begin{array}{l}\text { Final reviewers } \\
\text { blinding }\end{array}$ & $\begin{array}{l}\text { Incomplete } \\
\text { results }\end{array}$ & $\begin{array}{l}\text { Selective results } \\
\text { report }\end{array}$ \\
\hline $\begin{array}{l}\text { Diaféria G } \\
\text { et al, } 2013^{(2)} \\
\text { and } 2016^{(4)}\end{array}$ & RCT & unknown & unknown & $\begin{array}{l}\text { yes (participants) } \\
\text { no(professional } \\
\text { speech therapist) }\end{array}$ & $\begin{array}{c}\text { yes } \\
\text { (polysomnography) }\end{array}$ & unknown & unknown \\
\hline $\begin{array}{l}\text { Verma et al, } \\
2016^{(17)}\end{array}$ & CR & NR & NR & NR & NR & NR & NR \\
\hline $\begin{array}{l}\text { leto et al, } \\
2015^{(3)}\end{array}$ & RCT & unknown & unknown & $\begin{array}{c}\text { yes (participants) } \\
\text { no(professional } \\
\text { speech therapist) }\end{array}$ & $\begin{array}{c}\text { yes } \\
\text { (polysomnography) }\end{array}$ & unknown & $\begin{array}{l}\text { Treatment } \\
\text { recommendation, } \\
\text { low risk of bias }\end{array}$ \\
\hline $\begin{array}{l}\text { Guimarães } \\
\text { et al, 2009(1) }\end{array}$ & RCT & unknown & unknown & $\begin{array}{l}\text { yes (participants) } \\
\text { no(professional } \\
\text { speech therapist) }\end{array}$ & $\begin{array}{c}\text { yes } \\
\text { (polysomnography) }\end{array}$ & unknown & unknown \\
\hline $\begin{array}{l}\text { Silva et al, } \\
2007^{(18)}\end{array}$ & CR & NR & NR & NR & NR & NR & NR \\
\hline $\begin{array}{l}\text { Pitta et al, } \\
2007^{(19)}\end{array}$ & $\begin{array}{c}\text { CR2 } \\
\text { cases }\end{array}$ & NR & NR & NR & NR & NR & NR \\
\hline
\end{tabular}

Subtitles: $\mathrm{CR}=$ case report; $\mathrm{CE}=$ clinical study; $\mathrm{RCT}=$ randomized clinical trial; $\mathrm{NR}=$ no record

The two systematic literature reviews listed in our search differ in relation to the objectives and criteria of analysis (Table 1). Data from the literature review ${ }^{16}$ performed through meta-analysis attest for the positive effects of OMT in adults based in parameters from polysomnography, indicating approximately $50 \%$ decrease in $\mathrm{AlH}$, improvement in minimum blood oxygen saturation and snoring. However, the systematic literature review previously published ${ }^{15}$, with focus in the increase of muscle tonus with exercises did not present favorable effects for $\mathrm{AlH}$ reduction under five ${ }^{15}$. We should reinforce that given the criteria of the described literature review potential results above this level were not considered as they would be later ${ }^{16}$, understanding that the $\mathrm{AlH}$ criteria under five events per hour indicates remission of the disorder.

Considering two of the RCTs $s^{2,4}$, they originally correspond to the same study and although they bring additional information, the data are from the same subjects and so were counted only once in our systematic literature review.
The three RCT were analyzed reported on Table 2 observing, when possible, the possibility of bias according to the Cochrane Collaboration criteria for the development of systematic reviews of interventions ${ }^{20}$. Little information on this item could be recovered in the complete version of the published articles or even in the respective thesis, which were secondarily checked. To give an example, only one of the studies ${ }^{3}$ mentions the intention of treating, which is recommended in the cases of dropout or loss of subjects in the RCT and this being a better model for this type of study. The RCT also presented performance bias in the blinding of the professionals performing the clinical evaluations pre and post OMT. That is something important to be taken into account in future studies.

The last three studies: the clinical study ${ }^{17}$ and the case reports ${ }^{18,19}$ do not provide data related to possible biases. For the present literature review all types of studies were analyzed despite possible biases.

Data related to the establishment the studies' sample, type of Sleep Breathing Disorder, level of severity of the OSA and therapeutic parameters can be found in Table 3. 
Table 3. Description of data from the studies considering subjects characterization, type of disorder and level of OSA severity and therapeutic parameters

\begin{tabular}{|c|c|c|c|c|c|c|c|}
\hline \multirow{2}{*}{ Author, year } & \multicolumn{3}{|c|}{$\begin{array}{l}\text { Subjects characterization in the } \\
\text { studies }\end{array}$} & \multirow{2}{*}{$\begin{array}{l}\text { Type and } \\
\text { severity of } \\
\text { the OSA }\end{array}$} & \multirow{2}{*}{$\begin{array}{l}\text { Therapeutic procedures } \\
\text { (OMT) }\end{array}$} & \multirow{2}{*}{$\begin{array}{l}\text { Frequency/ } \\
\text { Period of OMT }\end{array}$} & \multirow{2}{*}{ Follow up } \\
\hline & $\mathbf{N}$ & Gender & $\begin{array}{c}\text { Age } \\
\text { (years) }\end{array}$ & & & & \\
\hline $\begin{array}{l}\text { Diaféria et al, } \\
2013^{(2)} \\
\text { and } 2016^{(4)}\end{array}$ & 27 & male & $45.2 \pm 13.0$ & $\begin{array}{l}\text { mild, } \\
\text { moderate } \\
\text { and severe } \\
\text { OSA }\end{array}$ & $\begin{array}{c}\text { Exercise program:Tongue, } \\
\text { soft palate, pharynx } \\
\text { musculature, facial } \\
\text { musculature.Functional: } \\
\text { breathing, swallowing and } \\
\text { mastication }\end{array}$ & $\begin{array}{l}12 \text { sessions } \\
3 \text { daily } \\
\text { practices, } 20 \\
\text { minutes each }\end{array}$ & $\begin{array}{l}\text { After } 3 \\
\text { weeks wash } \\
\text { out: decrease } \\
\text { in AHI }\end{array}$ \\
\hline $\begin{array}{l}\text { Verma et al, } \\
2016^{(17)}\end{array}$ & 20 & $\begin{array}{l}\text { male }(75 \%) \\
\text { female }(25 \%)\end{array}$ & $41.1 \pm 10.6$ & $\begin{array}{l}\text { mild and } \\
\text { moderate } \\
\text { OSA }\end{array}$ & $\begin{array}{l}3 \text { stages exercise } \\
\text { program:Tongue, soft palate, } \\
\text { facial musculature and } \\
\text { mandible musculature. }\end{array}$ & $\begin{array}{l}12 \text { sessions } \\
10 \text { repetitions } \\
5 \text { series per } \\
\text { day }\end{array}$ & NR \\
\hline $\begin{array}{l}\text { leto et al, } \\
2015^{(3)}\end{array}$ & 19 & $\begin{array}{l}\text { male }(57.9 \%) \\
\text { female }(42.1 \%)\end{array}$ & $48 \pm 14$ & $\begin{array}{l}\text { snoring, } \\
\text { mild and } \\
\text { moderate } \\
\text { OSA }\end{array}$ & $\begin{array}{l}\text { Nasal washShort exercise } \\
\text { programTongue, soft } \\
\text { palate, facial musculature. } \\
\text { Functional: mastication }\end{array}$ & $\begin{array}{c}12 \text { sessions } \\
\text { Daily practice } \\
3 \text { times a day, } \\
8 \text { minutes each }\end{array}$ & NR \\
\hline $\begin{array}{l}\text { Guimarães } \\
\text { et al, 2009(1) }\end{array}$ & 16 & male & 63 & $\begin{array}{l}\text { Moderate } \\
\text { OSA }\end{array}$ & $\begin{array}{c}\text { Nasal washExercise } \\
\text { program:Tongue, soft } \\
\text { palate, facial musculature } \\
\text { and mandible musculature. } \\
\text { Functional: speech, } \\
\text { breathing, swallowing and } \\
\text { mastication }\end{array}$ & $\begin{array}{l}12 \text { sessions } \\
\text { Daily practice } \\
30 \text { minutes } \\
\text { each }\end{array}$ & NR \\
\hline $\begin{array}{l}\text { Silva et al, } \\
2007^{(18)}\end{array}$ & 1 & female & 60 & Severe OSA & $\begin{array}{l}\text { Nasal washExercises } \\
\text { forTongue, soft palate, facial } \\
\text { musculature.Functional: } \\
\text { Breathing and mastication }\end{array}$ & $\begin{array}{l}12 \text { sessions } \\
\text { Note.:1 } 1^{\text {st }} \text { PSG } \\
10 \text { months } \\
\text { previous to } \\
\text { therapy) }\end{array}$ & NR \\
\hline $\begin{array}{l}\text { Pitta et al, } \\
2007^{(19)}\end{array}$ & 1 & male & 37 & Severe OSA & $\begin{array}{l}\text { Exercises forTongue, soft } \\
\text { palate, pharynx musculature, } \\
\text { facial musculature and } \\
\text { mandible musculature. }\end{array}$ & 16 sessions & NR \\
\hline
\end{tabular}

Subtitles: $\mathrm{N}=$ number of subjects; $\mathrm{OSA}=$ obstructive sleep apnea; OMT= orofacial myofunctional therapy; $\mathrm{AHI}=$ Apnea and hypopnea Index per hour of sleep; $N R=n 0$ record; $\mathrm{PSG}=$ Polysomnography

The three $\mathrm{RCT}^{1-4}$ counted on a control group as intended for this type of study. The subjects did not undergo OMT, only receiving orientations and/ or nasal wash as placebo effect in order to minimize performance bias. Trying to analyze the effects of OMT associated to other forms of therapy, other studies ${ }^{2,4}$ have considered four groups, one control group $(\mathrm{N}=24)$, one OMT group ( $\mathrm{N}=27), \mathrm{CPAP}(\mathrm{N}=27)$ and a mixed group (CPAP e OTM) $(\mathrm{N}=22)$. This literature review considered only the results referring to OMT alone, following the methodological criteria.
The analysis section of the studies ${ }^{1-4,17}$ did not include sample calculation, which we consider to be a relevant matter. The challenge of gathering a relevant number of participants in the groups, especially for this kind of studies is a known fact, mainly in the search for homogeneity in the sample. However, observing the number of subjects in the clinical studies' OMT group, we notice a gradual increase in that aspect through the years, which we consider to be a positive factor.

The Sleep Breathing Disorders and their level of severity have also changed through the years. Starting 
with clinical case reports of severe OSA ${ }^{19,20}$, going to RCT with moderate OSA ${ }^{1}$, to mild or moderate OSA ${ }^{3,17}$ to $\mathrm{RCT}^{2,4}$ with all three levels of OSA severity. We were able to notice that the search for data on OMT effects has grown for all levels of OSA.

Regarding the methodological therapeutic parameters applied to each of the studies ${ }^{1-4,17,19}$, the approach and procedures in OMT were the same considering the period of therapy, being prescribed 12 sessions, one time per week. They differ nevertheless in the selection of exercises, number of repetitions, frequency and period of daily practice and also in the type of functional approach. The specificities of the practices were not properly justified regarding the choices made in each of the studies.

The analysis section of the case reports are clearly more specific and direct considering the case matter. On those studies, the selected exercises are not described, nor is the amount of exercises. On the RCTs those descriptions are found. On one of the case reports ${ }^{17}$ the amount of exercises changes along three stages of practice: 13 exercises for the two first stages and seven for the third one. The other three RCTs ${ }^{1-4}$ seem to suggest the following up of exercises and functional practice progress without considering stages. Two of the studies indicate programs with a higher amount of exercises ${ }^{1,2,4}$ and another ${ }^{3}$ shows a great reduction of such number, maybe trying to facilitate the technique for the patient or because of the main focus of the study, which was primary snoring.
It is important to indicate that mostly because of the type of study, techniques were previously defined and equally applied for the entire study group in each of researches regardless of the myofunctional changes that each of the participants could present. For RCT studies that is a required procedure in order to observe the effects of a certain technique. However, studies with consistent justification for the exercise selection and its functional approach seem to be necessary to better fund the therapeutic practice targeted to those cases.

The description of therapeutic parameters only similar among the studies is probably due to the variety of aspects and matters that involve a orofacial myofunctional therapeutic approach, besides the recent presence of such therapy in the field of sleep disorders.

Other relevant data refer to the follow up of the studies in relation to the effects obtained with OMT. Only one of the studies in the present systematic review brought this important concern ${ }^{2,4}$, revealing a downsize of the results previously obtained. Considering that the follow up was only after a few weeks, it was possible to attest the necessity of maintaining the therapy program to solidify the results previously obtained. New studies, with medium and long term follow ups seem to be necessary.

The data regarding the methodological parameters for evaluation and reevaluation post OMT are found in Tables 4 and 5. Considering this aspect, the randomized trials follow similar parameters for evaluation and reevaluation and they are based on symptomatology data, specific anthropometric data and polysomnographic data. 
Table 4. Description of data considering the results with orofacial myofunctional therapy (OMYT) based on physiological parameters

\begin{tabular}{|c|c|c|c|c|c|c|c|c|}
\hline \multirow{3}{*}{ Author, year } & \multicolumn{4}{|c|}{ Anthropometric measurements } & \multicolumn{4}{|c|}{ Polysomnography } \\
\hline & \multicolumn{2}{|c|}{ BMI $\left(\mathrm{kg} / \mathrm{m}^{2}\right)$} & \multicolumn{2}{|c|}{ CC (cm) } & \multicolumn{2}{|c|}{ AHI (events/hour) } & \multicolumn{2}{|c|}{ Minimum Sp02 (\%) } \\
\hline & pre & post & pre & post & pre & post & Pre & post \\
\hline $\begin{array}{l}\text { Diaféria G } \\
\text { et al, } 2013^{(2)} \\
\text { and } 2016^{(4)}\end{array}$ & $25.0 \pm 7.4$ & $26.7 \pm 2.9$ & $41.6 \pm 3.7$ & $41.5 \pm 2.3$ & $28 \pm 22.7$ & $13.9 \pm 18.5^{\star}$ & $83.7 \pm 7.7$ & $84.9 \pm 8.8$ \\
\hline $\begin{array}{l}\text { Verma et al, } \\
2016^{(17)}\end{array}$ & $25.6 \pm 3.1$ & $25.4 \pm 3.2$ & $38.4 \pm 1.3$ & $37.8 \pm 1.6^{\star}$ & $20.1 \pm 9.1$ & $19.7 \pm 9.4$ & $87.6 \pm 1.1$ & $88.5 \pm 1.6^{*}$ \\
\hline $\begin{array}{l}\text { leto et al, } \\
2015^{(3)}\end{array}$ & $28.1 \pm 2.7$ & $28.2 \pm 2.8$ & $37.9 \pm 2.5$ & $37.5 \pm 2.4^{\star *}$ & $\begin{array}{c}25.4(22.1- \\
28.7) \\
\#\end{array}$ & $\begin{array}{c}18.1(15.4- \\
24.1) \\
\# * \star \star\end{array}$ & $85.5 \pm 7.5$ & $83.8 \pm 8.9$ \\
\hline $\begin{array}{l}\text { Guimarães } \\
\text { et al, 2009(1) }\end{array}$ & $29.6 \pm 3.8$ & $29.5 \pm 4.3$ & $39.6 \pm 3.6$ & $38.5 \pm 4.0^{*}$ & $22.4 \pm 4.8$ & $13.7 \pm 8.5^{\star}$ & $83 \pm 6$ & $85 \pm 7^{*}$ \\
\hline $\begin{array}{l}\text { Silva et al. } \\
2007^{(18)}\end{array}$ & 23.3 & NC & NC & NC & 44 & 3 & 83 & 92 \\
\hline Pitta et al. & 26.3 & 27.7 & NC & NC & 48.5 & 8.6 & 79 & 87 \\
\hline $2007^{11}$ & 22.2 & 22.2 & NC & NC & 40.4 & 3.3 & 77 & 83 \\
\hline
\end{tabular}

Subtitles: Data presenting mean and standard deviation. except for \#. which presents the results in median. minimum and maximum; $\mathrm{BMI}=$ body mass index; $\mathrm{CC}=$ cervical circumference; $\mathrm{AHI}=$ Apnea and Hypopnea Index per hour of sleep; Sp02 = blood minimum saturation; ${ }^{\mathrm{P}}$ significant $(<0.05)$ test $\mathrm{T}$; ${ }^{* *} \mathrm{P}$ significant considering test with variation according to period and group; $* \star * P$ relevant only for the group with moderate OSA; NR= no record.

Table 5. Description of data considering the results with orofacial myofunctional therapy (OMT) based on symptomatological parameters

\begin{tabular}{|c|c|c|c|c|c|c|c|c|}
\hline \multirow{3}{*}{ Author. Year } & \multicolumn{8}{|c|}{ Symptomatology } \\
\hline & \multicolumn{2}{|c|}{$\begin{array}{l}\text { Life quality } \\
\text { Sleep quality }\end{array}$} & \multicolumn{2}{|c|}{ ESS } & \multicolumn{2}{|c|}{ Intensity of snoring } & \multicolumn{2}{|c|}{ Frequency of snoring } \\
\hline & pre & post & pre & post & pre & post & pre & post \\
\hline \multirow[b]{2}{*}{$\begin{array}{l}\text { Diaféria G } \\
\text { et al. } 2013^{(2)} \\
\text { and } 2016^{(4)}\end{array}$} & \multirow[b]{2}{*}{$\begin{array}{c}\text { FOSQ } \\
\text { WHOQOL- } \\
\text { Bref SF-36(2) }\end{array}$} & FOSQ & \multirow[b]{2}{*}{$13.7 \pm 3.2^{(2)}$} & \multirow[b]{2}{*}{$7.5 \pm 3.7^{\star}$} & \multirow[b]{2}{*}{$8.5 \pm 2.3^{(4)}$} & \multirow[b]{2}{*}{$4.9 \pm 3.2^{*}$} & \multirow[b]{2}{*}{$7.7 \pm 2.3^{(4)}$} & \multirow[b]{2}{*}{$4.3 \pm 2.8^{*}$} \\
\hline & & $\begin{array}{c}\text { WHOQoL- } \\
\text { Bref * } \\
\text { SF-36* }\end{array}$ & & & & & & \\
\hline $\begin{array}{l}\text { Verma et al. } \\
2016^{(17)}\end{array}$ & NC & NC & $15.4 \pm 2.3$ & $13.6 \pm 3.1^{*}$ & $2.8 \pm 0.5$ & $1.7 \pm 0.6$ * & NC & NC \\
\hline $\begin{array}{l}\text { leto et al. } \\
2015^{(3)}\end{array}$ & $\begin{array}{c}\text { Pittsburgh } \\
6 \pm 3.2\end{array}$ & $\begin{array}{l}\text { Pittsburgh } \\
4 \pm 2.6^{*}\end{array}$ & $\begin{array}{c}7(3-11) \\
\#\end{array}$ & $7(4-10) \#$ & $\begin{array}{c}2(2-3) S \\
4(2.5-4) \mathrm{C} \\
\#\end{array}$ & $\begin{array}{c}2(1-2) S \\
1(1-2) C^{\star} \\
\#\end{array}$ & $\begin{array}{c}3(2-4) S \\
4(3-4) C \\
\#\end{array}$ & $\begin{array}{c}2(1-4) S \\
2(1.5-3) C^{*} \\
\#\end{array}$ \\
\hline $\begin{array}{l}\text { Guimarães } \\
\text { et al. } 2009^{(1)}\end{array}$ & $\begin{array}{l}\text { Pittsburgh } \\
10.2 \pm 3.7\end{array}$ & $\begin{array}{l}\text { Pittsburgh } \\
6.9 \pm 2.5^{*}\end{array}$ & $14 \pm 5$ & $8 \pm 6^{*}$ & $\begin{array}{c}3(3-4) \\
\#\end{array}$ & $\begin{array}{c}1(1-2)^{*} \\
\#\end{array}$ & $\begin{array}{c}4(4-4) \\
\quad \#\end{array}$ & $\begin{array}{c}3(1.5-3.5)^{*} \\
\#\end{array}$ \\
\hline $\begin{array}{c}\text { Silva et al. } \\
2007^{(18)}\end{array}$ & NR & NR & NR & NR & NR & NR & NR & NR \\
\hline \multirow{2}{*}{$\begin{array}{l}\text { Pitta et al. } \\
2007^{(19)}\end{array}$} & NR & NR & 12 & 10 & $\begin{array}{l}\text { Disturbs the } \\
\text { partner }\end{array}$ & mild & NR & NR \\
\hline & NR & NR & 13 & 7 & $\begin{array}{l}\text { Disturbs the } \\
\text { partner }\end{array}$ & mild & NR & NR \\
\hline
\end{tabular}

Subtitles: Data presenting mean and standard deviation. except for \#. which presents the results in median. minimum and maximum; ESS=Epworth Sleepiness Scale; * $P$ significant $(<0.05)$ test $T ; S=$ information given by the subject of the research; $C=$ information provided by the roommate; $N R=$ no record. 
Table 4 shows the data of the results obtained with OMT based in physiologic parameters and they show significant differences in relation to anthropometric measurements considering the reduction in cervical circumference without BMI reduction in three clinical studies $^{1,3,17}$. The authors indicate that the improvement in oropharynx musculature may have determined such reduction since the subjects did not lose weight and their BMI was not altered.

Considering physiologic data obtained with polysomnography, all three $\mathrm{RCT}^{1-4}$ revealed significant differences in OMT showing decrease in $\mathrm{AlH}$. It is worth to point out that in one of the studies ${ }^{3}$, which also considered subjects with primary snoring and mild OSA, the relevant statistic difference was only for the subjects with moderate OSA. The author justifies that the AlH for mild OSA is already close to the minimum limit and thus not provide significant reduction.

The two articles with case reports ${ }^{18,19}$ are the ones presenting a better improvement in the level of apnea with great differences in $\mathrm{AlH}$, maybe because they had an individual focus. Those studies also present improvement in the minimum $\mathrm{SpO} 2$, as well as in one of the ECR ${ }^{1}$ and the clinical essay ${ }^{17}$, indicating one other relevant beneficial effect of OMT.

In order to analyze the effects of OMT on snoring in an instrumental way, a $\mathrm{RCT}^{3}$ measured snoring recording it with a microphone and then presented a total snoring index considering sound intensity divided by the total period of sleep. The analysis of such data pre and post OMT, comparing the results in both groups (therapy and control) showed significant reduction of snoring considering the snoring index and also considering the total snoring index in the OMT group ${ }^{3}$.

The results in the studies referring to the symptomatology pre and post OMT are found in table 5, which brings the data in quality of life, quality of sleep, excessive daytime sleepiness, intensity and frequency of snoring, reported and analyzed with specific questionnaires.

Only one of the $\mathrm{RCT}^{2}$ brought data on quality of life using three different questionnaires (FOSQ ${ }^{21}$, WHOQoL-Bref ${ }^{22}$ and SF-36 ${ }^{23}$ ). Comparing the results of the group pre and post OMT. Significant differences were found in: physical domain of the instrument WHOQoL-Bref and functional quality of the SF-36, revealing the effects of OMT in those aspects.

The observation of the quality of sleep was reported in two studies ${ }^{1,3}$ using the Pittsburgh ${ }^{24}$ questionnaire. The data show improvement with significant differences post OMT, although not indicating in which components specifically.

The data on the symptom of daytime sleepiness were based on the Epworth Sleepiness Scale (ESS) ${ }^{9}$ in four of the clinical essays $s^{1-4,17}$ and in one of the case reports ${ }^{19}$. Excluding the results in one of the $\mathrm{RCT}^{3}$, the studies indicate a significant reduction of the symptom after a OMT program.

Considering the data related to snoring, the clinical studies analyzed the intensity and frequency of the snoring according to the Berlin questionnaire ${ }^{1,3,17}$ or the analogic subjective visual scale ${ }^{4}$. They indicate a reduction in intensity ${ }^{1,3,4,17}$ and frequency of snoring ${ }^{1,3,4}$. One of the $\mathrm{RCT}^{3}$ separates the Berlin questionnaire answers when applied to the subject himself or his roommate, showing significant improvement in the answers of the roommate when comparing pre and post data for the OMT and the control group. In general terms, the report on snoring by the patient himself is uncommon and when it happens is due to information previously given by the roommate. He is the one that listens to the subject snoring and is able to report on changes and is thus the most relevant information for that variable.

In relation to the case reports, one of them ${ }^{19}$ analyzed excessive daytime sleepiness and snoring data in two cases. The data followed the Epworth Sleepiness Scale (ESS) and show a relief of the symptom. The data on snoring, on its turn, followed a scale of 0 to 4 (0 = absence of snoring, $1=$ resonate; 2 = light snore, 3 = snoring disturbing partner, $4=$ snoring disturbing family). In both cases there was a reduction in the symptom post OMT. The other case report ${ }^{18}$ only brings information on high intensity snoring and the report of sleepiness previous to OMT, going to moderate snoring after OMT with evidence on polysomnographic data. The lack of data uniformity does not allow us to infer how those characteristics related to the effects of OMT in the study.

Considering the data in general, it is worth noticing that the clinical study ${ }^{17}$ and one of the RCTs ${ }^{3,4}$, statistical analysis were presented in terms of mean and standard deviation. However, two of the RCTs $s^{1,3,4}$ included median, minimum and maximum, probably because of the number of subjects in the sample. Methodological differences were also identified between the RCTs $s^{1-4}$ and the clinical study ${ }^{17}$. The RCTs compared changes pre and post OMT between the study and control groups after the indicated period and the results were statistically analyzed. The clinical study brought 
statistical analysis considering the changes in study group post OMT compared with data from previous evaluation. Regardless of those methodological differences, which can difficult the comparison of results, the studies confirm the positive effects of OMT for patients with OSA.

Systematic literature reviews are a growing tendency in the field of health sciences as to gather evidence on the practice of a certain line of action, trying to base changes in the works of prevention, diagnosis, treatment and rehabilitation. The privilege of a systematic literature review is the possibility of a detailed approach focused on answering precise questions. In the field of Speech, Language and Hearing Sciences, that is already a challenge, given the variety of the aspects involved in each of the fields of competence ${ }^{25,26}$. However, sleep studies in that context are a recent and interdisciplinary field of work and the search for literature reviews that recover the effects of therapies is necessary to guide upcoming studies as well as the clinical practice.

The present systematic literature review found that there are few controlled randomized trials with adults and they are necessary to provide scientific evidence to guide the eligibility criteria for undergoing OMT and also determine the applicable therapy procedures.

\section{CONCLUSION}

The present systematic literature review shows that the methodological parameters guiding orofacial myofunctional therapy programs for Sleep Breathing Disorders mostly compare data pre and post therapy based on the analysis of: symptomatology related to quality of life, quality of sleep, daytime sleepiness, intensity and frequency of snoring; anthropometric data related to body mass index and cervical circumference; physiological parameters measured with polysomnography related to Apnea and Hypopnea Index and blood minimum saturation.

The parameters for therapy are related to the practice of exercises for the orofacial and oropharynx musculature daily, reinforced by functional practice for the period of 3 months, with individual therapy one time per week.

The most relevant effects of the isolated orofacial myofunctional therapy in adults include: reduction of daytime sleepiness and snoring, better quality of sleep, partial decrease in the Apnea and Hypopnea Index and partial increase in the blood minimum saturation.
There have been few controlled randomized blind trials and they are important to attest the effects of the technique based on evidences and guiding the therapeutic decisions considering evaluation and diagnosis and the phenotype of the patient for an accurate prognosis.

\section{ACKNOWLEDGEMENTS}

Coordination for the Improvement of Higher Education Personnel (CAPES) National postdoctoral program in the Program of Graduate Studies in Speech Language Pathology and Audiology (PEPG/PUC-SP) at the Pontificate Catholic University of São Paulo.

\section{REFERENCES}

1. Guimarães KC, Drager LF, Genta PR, Marcondes BF, Lorenzi-Filho G. Effects of oropharyngeal exercises on patients with moderate obstructive sleep apnea syndrome. Am J Respir Crit Care Med. 2009;179(10):962-6.

2. Diaferia G, Badke L, Santos-Silva R, Bommarito S, Tufik S, Bittencourt L. Effect of speech therapy as adjunct treatment to continuous positive airway pressure on the quality of life of patients with obstructive sleep apnea. Sleep Med. 2013;14(7):628-35.

3. leto V, Kayamori F, Montes MI, Hirata RP, Gregório $M G$, Alencar AM et al. Effects of oropharyngeal exercises on snoring: a randomized trial. Chest. 2015;148(3):683-91.

4. Diaféria G, Santos-Silva R, Truksinas E, Haddad FLM, Santos R, Bommarito $S$ et al. Myofunctional therapy improves adherence to continuous positive airway pressure treatment. Sleep Breath. 2016;21(2):387-95.

5. Guimarães KC. Alterações no tecido mole de orofaringe em portadores de apneia do sono obstrutiva. J Bras Fonoaudiol.1999;1(1):69-75.

6. Steele CM. On the plausibility of upper airway remodeling as an outcome of orofacial exercise. Am J Respir Crit Care Med. 2009;179(10):858-9.

7. Dempsey JA, Veasey SC, Morgan BJOC. Pathophysiology of sleep apnea. Physiol Rev. 2010;90(1):47-112.

8. Piccin V, Bianchini E. A multidisciplinaridade no tratamento da apneia do sono: Fisioterapia e Fonoaudiologia juntas em prol do sucesso do tratamento da apneia. Rev Sono. 2017;10(2):13. 
9. Johns M. A new method for measuring daytime sleepiness: the Epworth sleepiness scale. Sleep. 1991;14(6):540-5.

10. Netzer N, Stoohs R, Netzer C, Clark K, Strohl K. Using the Berlin Questionnaire to identify patients at risk for the sleep apnea syndrome. Ann Intern Med. 1999;131(137):485-91.

11. Guilleminault C, Huang YS, Monteyrol PJ, Sato $\mathrm{R}$, Quo S, Lin $\mathrm{CH}$. Critical role of myofascial reeducation in pediatric sleep-disordered breathing. Sleep Med. 2013;14(6):518-25.

12. Lee SY, Guilleminault C, Chiu HY, Sullivan SS. Mouth breathing, "nasal disuse," and pediatric sleep-disordered breathing. Sleep Breath. 2015;19(4):1257-64.

13. Villa MP, Brasili L, Ferretti A, Vitelli O, Rabasco J, Mazzotta AR et al. Oropharyngeal exercises to reduce symptoms of OSA after AT. Sleep Breath. 2015;19(1):281-9.

14. Villa MP, Evangelisti M, Martella S, Barreto M, Del Pozzo M. Can myofunctional therapy increase tongue tone and reduce symptoms in children with sleep-disordered breathing? Sleep Breath. 2017. Mar 18. [Epub ahead of print]

15. Valbuza JS, De Oliveira MM, Conti CF, Prado LBF, De Carvalho LBC, Do Prado GF. Methods for increasing upper airway muscle tonus in treating obstructive sleep apnea: Systematic review. Sleep Breath. 2010;14(4):299-305.

16. Camacho M, Certal V, Abdullatif J, Zaghi S, Ruoff $\mathrm{CM}$, Capasso R et al. Myofunctional therapy to treat obstructive sleep apnea: a systematic review and meta-analysis. Sleep. 2015;38(5):669-75.

17. Verma RK, Johnson-J JR, Goyal M, Banumathy N, Goswami U, Panda NK. Oropharyngeal exercises in the treatment of obstructive sleep apnoea: our experience. Sleep Breath. 2016;20(4):1193-201.

18. Silva LM de P, Aureliano FT dos S, Motta AR. Atuação fonoaudiológica na síndrome da apnéia e hipopnéia obstrutiva do sono: relato de caso. Rev. CEFAC. 2007;9(4):490-6.

19. Pitta DB e S, Pessoa AF, Sampaio ALL, Rodrigues RN, Tavares MG, Tavares P. Terapia miofuncional oral aplicada a dois casos de síndrome da apnéia obstrutiva do sono grave. Arq Int Otorrinolaringol. 2007;11(3):350-4.

20. Carvalho APV, Silva VGA. Avaliação do risco de viés de ensaios clínicos randomizados pela ferramenta da colaboração Cochrane. Diagnóstico Trat. 2013;18(1):38-44.
21. Weaver T, Laizner A, Evans L, Maislin G, Chugh D, Lyon $\mathrm{K}$ et al. An instrument to measure functional status outcomes for disorders of excessive sleepiness. Sleep. 1997;20(10):835-43.

22. Skevington SM, Lotfy M, O'connell KA. The World Health Organizations WHOQOL-BREF quality of life assessment: Psychometric properties and results of the international field trial A Report from the WHOQOL Group. Qual Life Res. 2004;13(2):299-310.

23. Ciconelli RM, Ferraz MB, Santos W, Meinão I, Quaresma MR. Tradução para a língua portuguesa e validação do questionário genérico de avaliação de qualidade de vida SF-36 (Brasil SF-36). Rev Bras Reumatol. 1999;39(3):143-50.

24. Buysse D, Reynolds C, Monk T, Berman S, Kupfer D. The Pittsburgh Sleep Quality Index: a new instrument for psychiatric practice and research. Psychiatry Res. 1989;28(2):193-213.

25. De-la-Torre-Ugarte-Guanilo MC, Takahashi RF, Bertolozzi MR. Systematic review: general notions. Rev Esc Enferm USP. 2011;45(5):1260-6.

26. Cunha MC. Literature review: a review with a focus on the systematic reviews. CoDAS. 2015;27(5):409-10. 